Article

\title{
Supplementary Far-Red Light Did Not Affect Tomato Plant Growth or Yield under Mediterranean Greenhouse Conditions
}

\author{
Onofrio Davide Palmitessa ${ }^{1, *(\mathbb{C})}$, Beniamino Leoni ${ }^{1}$, Francesco Fabiano Montesano ${ }^{2}{ }^{(D}$, \\ Francesco Serio ${ }^{2}{ }^{(1)}$, Angelo Signore ${ }^{1}\left[{ }^{(1)}\right.$ and Pietro Santamaria ${ }^{1}(\mathbb{C})$ \\ 1 Department of Agricultural and Environmental Science, University of Bari Aldo Moro, via Amendola 165/a, \\ 70126 Bari, Italy; beniamino.leoni@uniba.it (B.L.); angelo.signore@uniba.it (A.S.); \\ pietro.santamaria@uniba.it (P.S.) \\ 2 Institute of Sciences of Food Production, National Research Council of Italy, 70126 Bari, Italy; \\ francesco.montesano@ispa.cnr.it (F.F.M.); francesco.serio@ispa.cnr.it (F.S.) \\ * Correspondence: onofrio.palmitessa@uniba.it; Tel.: +39-33-34-496-718
}

Received: 2 November 2020; Accepted: 23 November 2020; Published: 24 November 2020

check for updates

\begin{abstract}
In the Mediterranean region, tomato plants are often cultivated in two short cycles per year to avoid the heat of summer and the low solar radiation of winter. Supplementary light (SL) makes it possible to cultivate during the dark season. In this experiment, a tomato F1 hybrid cultivar DRW7723 was cultivated in a greenhouse for a fall-winter cycle. After transplant, light emitting diode (LED) interlighting, with two light spectra (red + blue vs. red + blue + far-red) was applied as SL. Plant growth, yield, gas exchange, nutrient solution (NS) consumption, and fruit quality were analyzed. In general, the effects of adding far-red radiation were not visible on the parameters analyzed, although the yield was $27 \%$ higher in plants grown with SL than those grown without. Tomatoes had the same average fresh weight between SL treatments, but the plants grown with SL produced $16 \%$ more fruits than control. Fruit quality, gas exchange and NS uptake were not influenced by the addition of far-red light. Interlighting is, therefore, a valid technique to increase fruit production in winter but at our latitude the effects of adding far-red radiation are mitigated by available sunlight.
\end{abstract}

Keywords: light emitting diodes (LED); interlighting; gas exchange; water use efficiency (WUE)

\section{Introduction}

Tomato (Solanum lycopersicum L.) is a short-lived perennial plant, generally cultivated under greenhouse conditions to obtain year-round production for fresh-market consumption, especially in soilless cultivation systems [1]. At northern latitudes, plants are usually transplanted in December and produce from March to November, while in areas with mild climate, such as the Mediterranean, growers prefer to transplant in late summer or autumn, producing tomatoes until late summer of the following year [1]. At northern latitudes, tomato growers opt to stay out of production between November and December, when the outside climate is rainy and cold and the daily light integral (DLI) is low, whereas in the Mediterranean region, the tomato plant cycle is stopped in early summer to avoid the need for greenhouse cooling [1]. Nevertheless, also in southern regions, the amount of natural light in late fall, winter and early spring has been shown to be a limiting factor for yield $[2,3]$.

In so-called "cold" (unheated) Mediterranean greenhouses, two short cycles are often completed per year (autumn and spring), leaving short production breaks when mid-summer (extremely hot) and mid-winter (low DLI and temperature) climate conditions are unfavorable [4]. However, the practice 
of performing two crop cycles per year requires two transplant operations which increase production costs and shorten the harvesting period. This is why a year-round cycle is preferable in greenhouses.

To increase tomato yield in a year-round crop cycle, especially in winter, supplementary light (SL) is needed $[2,5,6]$. High-pressure sodium lamps are currently the most widely installed in northern greenhouses [7], but are uncommon in Mediterranean greenhouses due to their low electrical efficiency and large heat output [8]. Light emitting diodes (LED) are a rapidly developing lighting technology [9], capable of high luminous flux with high electrical efficiency and low radiant heat output [10]. With LED it is also possible to optimize spectral quality for different plants and physiological processes [11]. The major wavelengths for photosynthesis are blue (B) and red (R). Peaks in photosynthetic efficiency are recorded at $440(B)$, and 620 and $670(\mathrm{R}) \mathrm{nm}( \pm 10 \mathrm{~nm})$ [12]. The photosynthetically active photon flux density increases if plants exploit (on $\mathrm{R}+\mathrm{B}$ background) far-red (FR) light between 700 and $750 \mathrm{~nm}$ [13]. Although FR light alone does not influence photosynthesis and plant growth [14], it has been shown to increase the photochemical efficiency of photosystem II and the leaf net photosynthesis rate of lettuce [15]. In a recent greenhouse study (West Lafayette, Indiana) it was found that LED interlighting, with FR in addition to red light $(\mathrm{R}+\mathrm{FR})$, did not modify tomato fresh weight ( $\mathrm{R} v \mathrm{v}$. $R+F R)$, whereas fruit fresh weight was higher under $R+F R$ than without interlighting [16]. In fact, additional FR on a R and B background is known to increase tomato fruit dry mass production; this is mainly due to an increase in the fraction of dry mass partitioned to the fruit [17]. However, FR radiation is abundant in sunlight [14] and while for indoor cultivations it is fundamental to use FR on a R + B background to improve photosynthesis and obtain high yields, the FR solar radiation component coming into a greenhouse could be sufficient for plant photosynthesis and growth.

On the basis of these considerations, we studied two different LED spectra ( $R+B$ vs. $R+B+F R)$ as SL to produce tomatoes during an autumn-winter cycle. The aims were to evaluate the effect of LED interlighting on tomato plant growth, yield, photosynthesis, fruit quality and nutrient solution consumption.

\section{Materials and Methods}

\subsection{Experimental Setup}

The experimental work was carried out at the experimental farm "La Noria" of the National Research Council Institute of Food Production Science (Mola di Bari, Italy $\left(41.062156^{\circ} \mathrm{N}, 17.066914^{\circ} \mathrm{E}\right)$ ) in an unheated polymethacrylate greenhouse with a maximum height of $4.5 \mathrm{~m}$.

\subsection{Plant Material and Growing Conditions}

The F1 hybrid tomato (Solanum lycopersicum L.) cultivar used was DRW 7723 (De Ruiter Seeds). The plants were grown in rockwool cubes (Grodan, $7.5 \times 7.5 \times 6.5 \mathrm{~cm}$ ) until the fourth true leaf stage (9 September 2019), when they were transplanted to rockwool slabs (Grodan Vital, $100 \times 15 \times 7.5 \mathrm{~cm}$ ) and placed in aluminum trough benches (length $6 \mathrm{~m}$, width $0.26 \mathrm{~m}$, slope $1 \%$, distance between benches $1.2 \mathrm{~m}$ ). Four plants were transplanted $0.25 \mathrm{~m}$ apart in each slab. The experimental layout consisted of eleven trough benches, each hosting sixteen plants (nine benches for the experimental units, and two benches as external guard rows which also included the first and last two plants in each row). The plants were trained vertically and topped at the seventh cluster. Periodic operations of binding, lateral stem, and basal leaf pruning were carried out. The greenhouse temperature was controlled by natural ventilation through ridge openings, set to open automatically above $20^{\circ} \mathrm{C}$. Pollination was guaranteed by introduction of bumblebees (Bombus terrestris L.) into the greenhouse. Temperature and relative humidity were recorded by a CR1000 datalogger (Campbell Scientific, Logan, UT, USA).

\subsection{Nutrient Solution (NS) Management}

The NS was supplied by self-compensating drip emitters (Netafim, Tel Aviv, Israel), one per plant, with a flow rate of $4 \mathrm{~L} \mathrm{~h}^{-1}$. Three different NSs were used during the experiment according to the 
phenological phase of the plants. From transplant to flowering of the third trusses, NS composition in mg L ${ }^{-1}$ was: $134 \mathrm{~N}^{-N_{3}}, 10 \mathrm{~N}-\mathrm{NH}_{4}, 161 \mathrm{~K}, 50 \mathrm{P}, 25 \mathrm{Mg}, 124 \mathrm{Ca}, 33 \mathrm{~S}$. From flowering of the third trusses

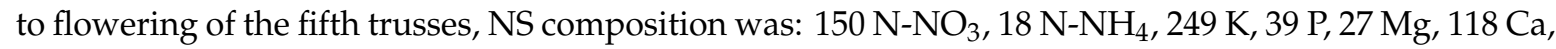

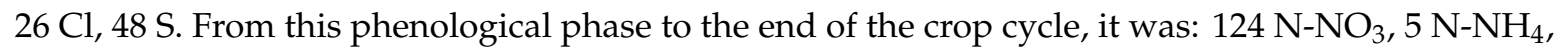
$300 \mathrm{~K}, 41 \mathrm{P}, 12 \mathrm{Mg}, 94 \mathrm{Ca}, 19 \mathrm{Cl}, 47 \mathrm{~S}$. Micronutrient composition was kept constant during the growing cycle according to Hoagland and Arnon [18]. A 100 L tank containing NS was situated at the lower end of each trough bench. The NS was re-circulated according to closed-cycle management and was never discharged during the growing cycle. The fertigation schedule was set to avoid water stress, so the number of irrigation events was adjusted during the growing cycle, depending on environmental conditions and plant stage. Three times per week the tank was topped up with fresh NS and the amount added was used to calculate plant consumption of NS. pH and electrical conductivity (EC) were measured before and after each addition to the tank.

\subsection{Supplementary Light Treatments}

Supplementary light (SL) was provided by LED interlight fixtures. Two modules with the same light spectra ("GreenHouse Interlight" produced by C-Led, Imola (BO), Italy), measuring $2490 \times 110 \times 57 \mathrm{~mm}$, were placed above the plants of six benches. Each module carried two series of LEDs with $120^{\circ}$ luminous flux angle. Supplementary photosynthetic photon flux density (PPFD) was $170 \mu \mathrm{mol} \mathrm{m} \mathrm{m}^{-2} \mathrm{~s}^{-1}$ at a horizontal distance of $30 \mathrm{~cm}$ from the lamp. Two light spectra were tested: Red $(660 \mathrm{~nm})+$ Blue $(440 \mathrm{~nm})(\mathrm{R}+\mathrm{B})$ and red + blue + far red $(730 \mathrm{~nm})(\mathrm{R}+\mathrm{B}+\mathrm{FR})$. The light spectrum ratios were: 4 (Red): 1 (blue) for $R+B$ (Figure 1a) and 4 (red): 1 (Blue): 1 (far red) for FR (Figure 1b). Natural light (NL, no supplementary lighting, three benches) was used as the control. The interlight modules were placed $25 \mathrm{~cm}$ below the apical meristem and the height was adjusted once a week to maintain a constant distance between the apical meristem and the fixtures, in order to ensure uniform light distribution and intensity. The light treatments started on 9 September with the LED modules above the apical meristems (the plants were $20 \mathrm{~cm}$ tall) and continued until the plants reached a height of $40 \mathrm{~cm}$. The supplementary lighting was operated automatically by a system composed of a CR1000 datalogger (Campbell Scientific, Logan, UT, USA) and a quantum sensor (LI-190R, LI-COR, Lincoln, $\mathrm{NE}, \mathrm{USA}$ ). For $16 \mathrm{~h} \cdot \mathrm{d}^{-1}$ (from 5:00 to 21:00), the system calculated incoming sunlight in the greenhouse on a four-second basis, and turned on the LED light bars whenever the ambient photosynthetic photon flux density (PPFD) dropped below $200 \mu \mathrm{mol} \mathrm{m}{ }^{-2} \mathrm{~s}^{-1}$. The bars remained on until sunlight PPFD again rose above this set-point.

\subsection{Daily Light Integral and Total Light Integral}

Daily light integral (DLI) describes the rate at which photosynthetically active radiation is delivered over a 24-h period [19], while the total light integral (TLI) is the sum of the DLIs obtained during the experiment. To calculate the DLI under NL conditions, we summed daily PPFDs measured by the quantum sensor every $10 \mathrm{~min}$ and multiplied the values obtained by $600 \mathrm{~s}$. To calculate the DLI provided by SL, we multiplied the PPFD $\left(170 \mu \mathrm{mol} \mathrm{m}^{-2} \mathrm{~s}^{-1}\right)$ by the time (seconds) the LEDs were on each day. To calculate the DLI provided to plants grown under SL conditions (NL + SL), we added the DLI provided by NL to the DLI supplied by SL.

\subsection{Growth Analysis, Yield, Fruit Dry Weight and Total Soluble Solids}

Starting from the day of transplant, every 20 days a plant from each experimental unit was harvested and used to measure the following growth parameters: fresh and dry weight of leaves, stem and roots; number and fresh and dry weight of fruits. 

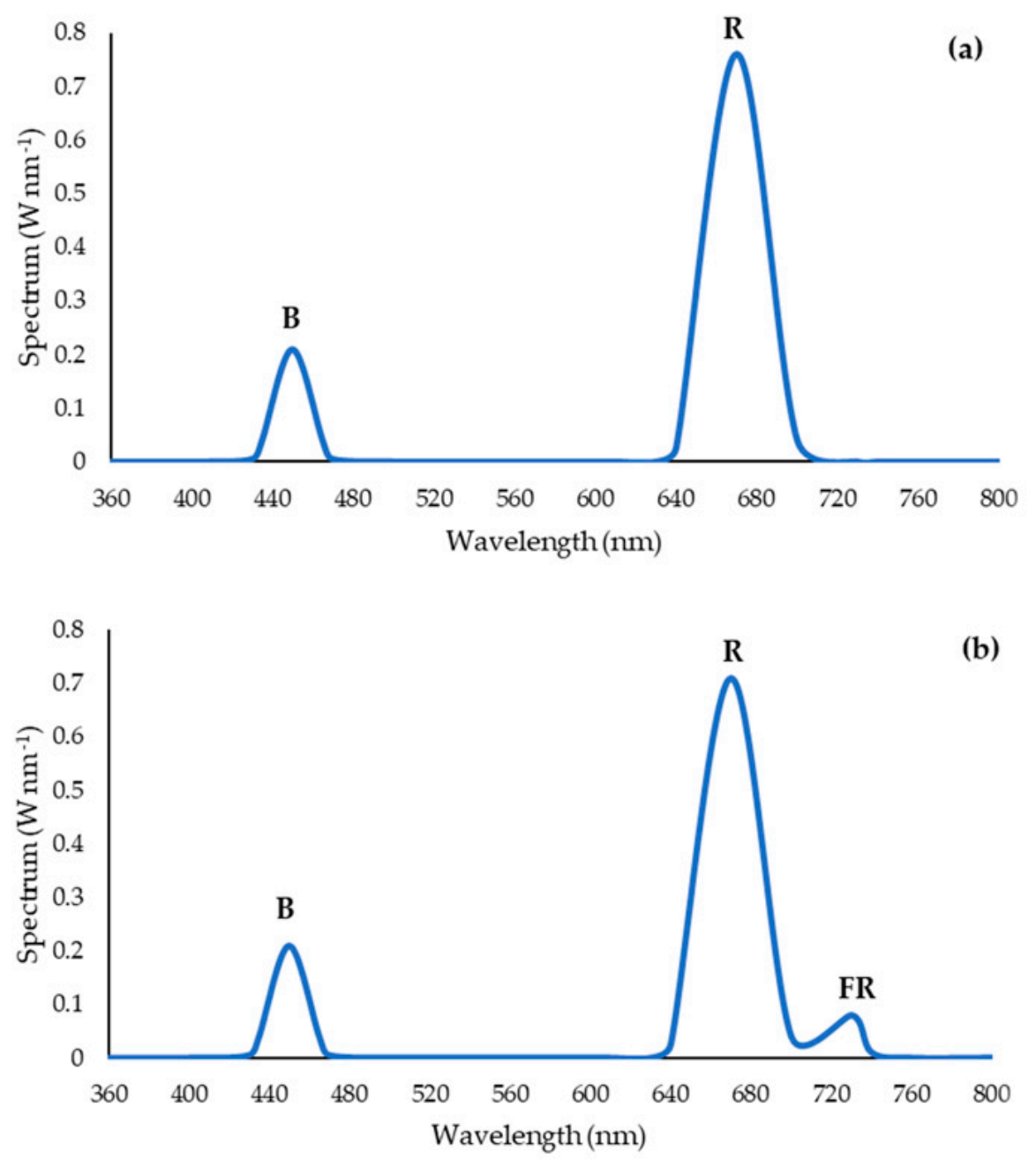

Figure 1. Light spectra of R+B LED interlight (a) and $R+B+F R$ interlight (b), in $W \mathrm{~nm}^{-1}$.

Harvesting started on 7 December 2019 and lasted until 6 February 2020. The tomatoes were harvested by picking single fruits from trusses at "color break" (when color turned from green to red). The tomatoes were divided into marketable and unmarketable (according to the marketing standards for tomatoes set by EC Regulation no. 790/2000 dated 14 April 2000). Unmarketable tomatoes were counted, weighed and discarded, while marketable fruits were divided into three classes, Extra, Class I, and Class II, counted and weighed. Extra tomatoes were divided into size classes based on equatorial fruit diameter (mm): 35-40, 41-47, 48-57, 58-67, 68-82, and 83-102. The immature tomatoes on the plant at the end of the experiment were harvested, weighed, counted and considered as "potential production". Total soluble solids (TSS) and dry weight (DW) were only determined for the Extra class. For TSS measurement, three tomatoes per experimental unit and per harvest were randomly selected and TSS content was determined using a portable reflectometer (Brixstix BX $100 \mathrm{Hs}$; Techniquip Corp., Livermore, CA, USA). Dry weight (DW) was obtained by placing samples in a forced-draft oven at $65^{\circ} \mathrm{C}$ until constant weight.

\subsection{Gas Exchange Measurements}

Photosynthesis net rate $\left(\mathrm{A}, \mu \mathrm{mol} \mathrm{CO} \mathrm{CO}^{-2} \mathrm{~s}^{-1}\right)$, stomatal conductance $\left(g_{s}, \mathrm{~mol} \mathrm{H}_{2} \mathrm{O} \mathrm{m}^{-2} \mathrm{~s}^{-1}\right)$, transpiration rate $\left(\mathrm{E}, \mathrm{mol} \mathrm{H} \mathrm{O} \mathrm{m}^{-2} \mathrm{~s}^{-1}\right)$ and intercellular $\mathrm{CO}_{2}$ concentration $\left(\mathrm{C}_{\mathrm{i}}, \mu \mathrm{mol} \mathrm{CO} \mathrm{Col} \mathrm{air}^{-1}\right)$ were also measured, 63 DAT, with the LI-6400 photosynthesis system (LI-COR, Lincoln, NE, USA), using a transparent cuvette (enclosed leaf area: $6 \mathrm{~cm}^{2}$ ). Leaflets were enclosed in the cuvette at $400 \pm 0.7 \mu$ bar $\mathrm{CO}_{2}, 250 \pm 1.8 \mu \mathrm{mol}$ photons $\mathrm{m}^{-2} \mathrm{~s}^{-1}, 20.0 \pm 0.5^{\circ} \mathrm{C}$ cuvette temperature, $70 \pm 1 \% \mathrm{RH}$ 
and a flow rate of $500 \mu \mathrm{mol} \mathrm{s}{ }^{-1}$. Once they had reached stability, $g_{s}$ and $E$ were logged 10 times at $30 \mathrm{~s}$ intervals; these values were later averaged over the nine biological replicates to improve accuracy.

\subsection{Experimental Design and Statistical Analysis}

The supplementary light treatments were arranged in a randomized block design with three replications. All data underwent analysis of variance (ANOVA) using the General Linear model (GLM; SAS Software, Cary, NC, USA). The experimental factors were fixed by one-way analysis of variance (ANOVA) and the orthogonal contrasts technique was used to establish differences between means (two contrasts): (1) NL vs. LED; (2) R + B vs. R + B + FR.

\section{Results}

\subsection{Greenhouse Climatic Conditions}

Air temperature in the greenhouse showed a decreasing trend from transplant (September) to the end of the cycle (January; Figure 2a). In the first days after transplant (DAT), greenhouse average daily temperature was $26.2 \pm 1.0^{\circ} \mathrm{C}$, compared to $15.2 \pm 1.0^{\circ} \mathrm{C}$ in the last days of the cycle (Figure 2a). The highest temperature peak was $41.4^{\circ} \mathrm{C}$, recorded 12 DAT (Figure 2a), and the lowest was $3.6^{\circ} \mathrm{C}$, recorded 125 DAT (Figure 2a). Relative humidity (RH) increased from 5 to 52 DAT and subsequently was almost stable at $53 \%$ to the end of the growth cycle (Figure 2b). From 5 to 21 DAT, average daily RH was $63.5 \pm 5.5 \%$; from 22 to 52 DAT it was $72.2 \pm 6.1 \%$ (Figure $2 b$ ). Similar values persisted until the end of the cycle (Figure $2 b$ ). Finally, a minimum RH of $29 \%$ was recorded 13 DAT during the day, and a maximum of $94 \%$ was recorded 64 DAT at night (Figure $2 \mathrm{~b}$ ).

\subsection{Daily Light Integral (DLI) and Total Light Integral (TLI)}

During the experiment, the average NL + SL DLI was $12.1 \pm 0.5 \mathrm{~mol} \mathrm{~m}^{-2} \mathrm{~d}^{-1}$ with the highest value measured on 28 DAT $\left(13.0 \mathrm{~mol} \mathrm{~m}^{-2} \mathrm{~d}^{-1}\right)$ and the lowest value measured on 31 DAT $\left(11.4 \mathrm{~mol} \mathrm{~m}^{-2} \mathrm{~d}^{-1}\right)$. The average DLI provided by LED to the plants increased from September to December and decreased in the last days of cultivation, when outside solar radiation increased (Figure 3). In detail, from 5 to 21 days after transplant (DAT), the average daily period of supplementary light (SL) was $9.4 \pm 1.2 \mathrm{~h}$, from 22 to 52 DAT it was $10.9 \pm 9.4 \mathrm{~h}$, from 53 to 82 DAT it was $13.7 \pm 1.4 \mathrm{~h}$, from 83 to 113 DAT it was $14.2 \pm 1.3 \mathrm{~h}$ and from 114 to $137 \mathrm{DAT}$ it was $13.1 \pm 1.0 \mathrm{~h}$ (Figure 3). On the other hand, the trend of solar radiation DLI decreased from September to the end of the growth cycle (Figure 3). On average, plants grown with SL received $11.7 \pm 0.9 \mathrm{~mol} \mathrm{~m}^{-2} \mathrm{~d}^{-1}$ while those grown only with NL received $3.08 \pm 1.5 \mathrm{~mol} \mathrm{~m}^{-2} \mathrm{~d}^{-1}$ (Figure 3). From 5 to 21 DAT, plants grown with SL received 55\% more DLI than plants grown with NL $\left(6.8 \pm 0.9\right.$ vs. $\left.5.6 \pm 1.0 \mathrm{~mol} \mathrm{~m}^{-2} \mathrm{~d}^{-1}\right)$, from 22 to 52 DAT they received $67 \%$ more $\left(7.8 \pm 1.0(\mathrm{SL})\right.$ vs. $\left.3.8 \pm 0.6 \mathrm{~mol} \mathrm{~m}^{-2} \mathrm{~d}^{-1}(\mathrm{NL})\right)$, from 53 to 82 DAT the DLI was $81 \%$ more $\left(9.9 \pm 1.1\right.$ (SL) vs. $\left.2.4 \pm 1.2 \mathrm{~mol} \mathrm{~m}^{-2} \mathrm{~d}^{-1}(\mathrm{NL})\right)$, from 83 to 137 DAT the DLI difference between SL and $\mathrm{NL}$ increased to $85 \%\left(10.2 \pm 0.9(\mathrm{SL})\right.$ vs. $1.9 \pm 0.7 \mathrm{~mol} \mathrm{~m}^{-2} \mathrm{~d}^{-1}$ (NL; Figure 3). Considering the entire crop cycle, plants grown with LED interlighting received a TLI of $1599 \mathrm{~mol} \mathrm{~m}^{-2}$, while plants grown with NL received $419 \mathrm{~mol} \mathrm{~m}^{-2}$ (Figure 3). Tomato plants grown with SL, therefore, received 3.8 times more photosynthetically active photon flux density than tomato plants grown only with NL (Figure 3). Finally, the total electrical power drawn by the LED interlighting was $496 \mathrm{~kW}$ per bench (Figure 3). 


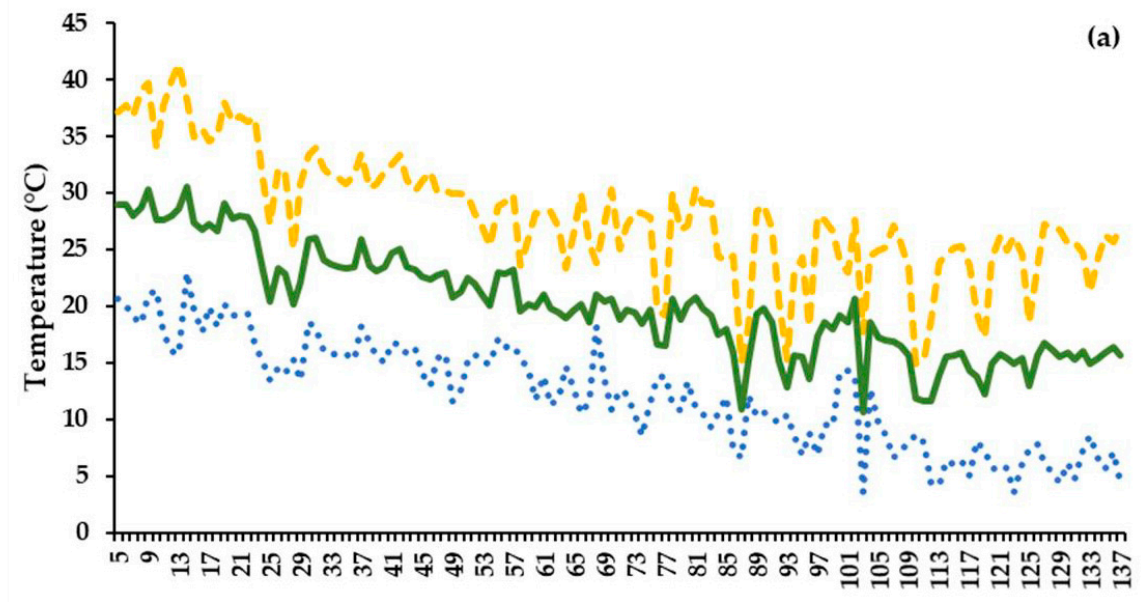

Day after transplanting(DAT)

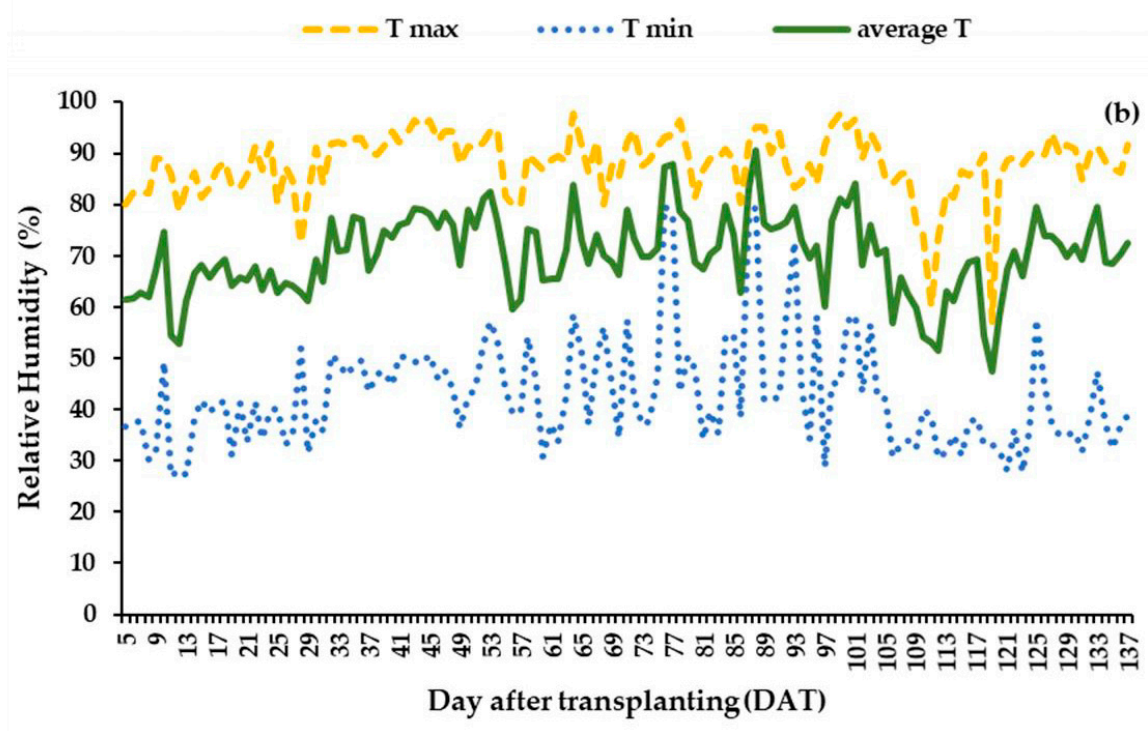

$---\mathrm{RH} \max \quad \ldots . . \mathrm{RH} \min \quad$ average $\mathrm{RH}$

Figure 2. Maximum ( $\mathrm{T} \max$ ), minimum ( $\mathrm{T} \min$ ) and average (average $\mathrm{T}$ ) daily temperature in the greenhouse during the crop cycle (a). Maximum (RH max), minimum ( $\mathrm{RH}$ min) and average (average $\mathrm{RH})$ daily relative humidity in the greenhouse during the crop cycle (b).

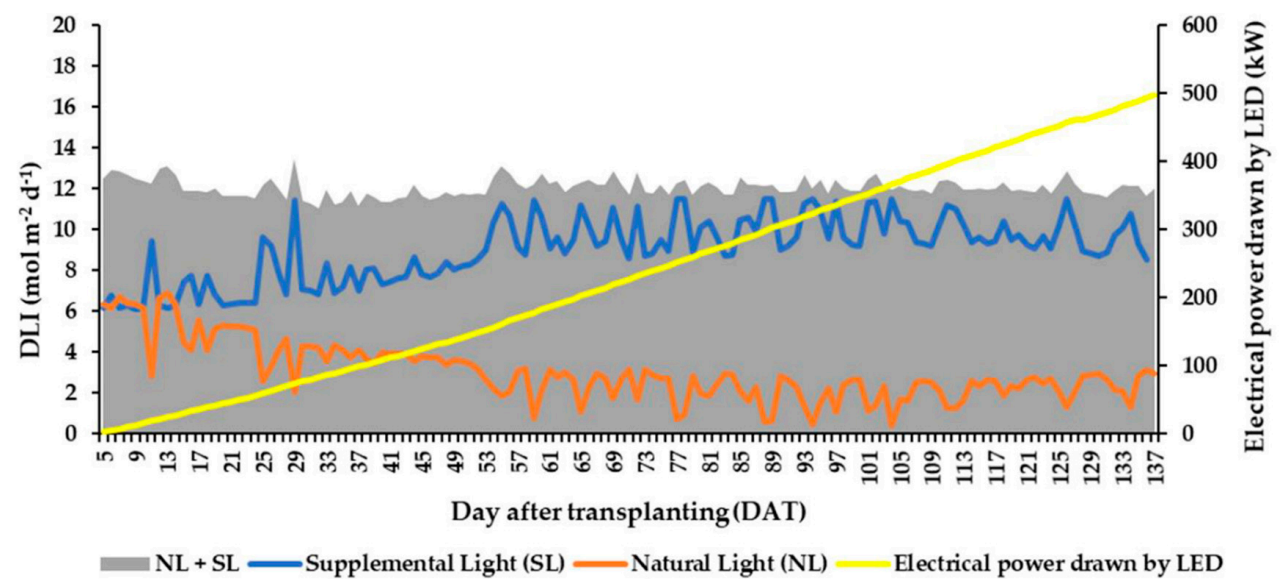

Figure 3. Daily light integral (DLI) from sunlight (Natural Light, NL), LED interlighting (Supplementary Light, SL), total DLI from sunlight and LED (NL + SL), and electrical power drawn by LED interlighting during cultivation (from September to December). 


\subsection{Growth Analysis and Gas Exchange}

On average, 67 DAT, plants grown with $\mathrm{R}+\mathrm{B}$ and $\mathrm{R}+\mathrm{B}+\mathrm{FR}$ interlighting showed leaves with a DW $9 \%$ higher than plants grown under NL conditions (Table 1). At same time, plants grown with $\mathrm{R}+\mathrm{B}+\mathrm{FR}$ had leaves with a DW $6 \%$ higher than plants grown with $\mathrm{R}+\mathrm{B}$ interlighting (Table 1). Dry weight of stem and fruits was not influenced by light treatment, their values averaging 8.1 and

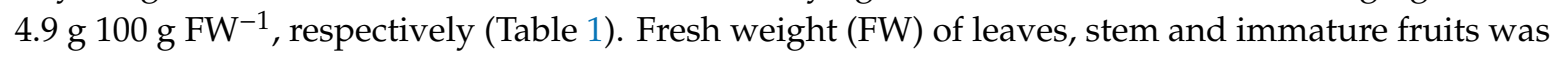
not influenced by light treatments (Table 1). The same results were obtained for the other destructive measurements conducted 88, 110 and 137 DAT (Supplementary Tables S1-S3). Light treatments did not influence gas exchange parameters (Table 2). On average, $A$ was $8.58 \pm 0.56 \mu \mathrm{mol} \mathrm{CO}_{2} \mathrm{~m}^{-2} \mathrm{~s}^{-1}$, $g_{s}$ was $0.347 \pm 0.10 \mathrm{~mol} \mathrm{H}_{2} \mathrm{O} \mathrm{m}^{-2} \mathrm{~s}^{-1}, C_{i}$ was $338 \pm 6.0 \mu \mathrm{mol} \mathrm{CO}_{2} \mathrm{~mol}^{-1}$, and $E$ was $3.72 \pm 0.60 \mathrm{~mol}$ $\mathrm{H}_{2} \mathrm{O} \mathrm{m}^{-2} \mathrm{~s}^{-1}$ (Table 2).

Table 1. Effects of light conditions on fresh weight (FW) and dry weight (DW) of fruits, leaves, and stems.

Values are average \pm DS of three replications 67 DAT.

\begin{tabular}{ccccccc}
\hline & Leaves FW & Stem FW & Fruits FW & Leaves DW & Stem DW & Fruits DW \\
\hline Supplemental light (SL) & & g plant $^{-1}$ & & & g 100 g FW \\
Control (NL) & $692.4 \pm 102.4$ & $380.8 \pm 47.7$ & $380.8 \pm 39.9$ & $7.6 \pm 0.3$ & $8.3 \pm 0.8$ & $4.3 \pm 0.8$ \\
R + B & $623.9 \pm 88.7$ & $368.3 \pm 35.6$ & $374.8 \pm 76.3$ & $8.0 \pm 0.1$ & $7.7 \pm 0.6$ & $5.4 \pm 0.6$ \\
R + B + FR & $561.5 \pm 63.8$ & $375.8 \pm 79.2$ & $411.7 \pm 67.0$ & $8.5 \pm 0.2$ & $8.4 \pm 0.7$ & $4.9 \pm 0.6$ \\
Significance $(1)$ & & & & & NS & NS \\
NL vs. SL & NS & NS & NS & $*$ & NS & NS \\
R + B vs. R + B + FR & NS & NS & NS & & \\
\hline
\end{tabular}

(1) Significance: * and ${ }^{* *}$ respectively for $p \leq 0.05$ and $p \leq 0.01$; NS, not significant.

Table 2. Effects of light conditions on photosynthesis net rate $\left(\mathrm{A}, \mu \mathrm{molCO} \mathrm{Cm}^{-2} \mathrm{~s}^{-1}\right)$, stomatal conductance $\left(g_{s}, \mathrm{~mol} \mathrm{H}_{2} \mathrm{O} \mathrm{m}^{-2} \mathrm{~s}^{-1}\right)$, transpiration rate $\left(\mathrm{E}, \mathrm{mol} \mathrm{H} \mathrm{O}^{-2} \mathrm{~s}^{-1}\right)$ and intercellular $\mathrm{CO}_{2}$ concentration $\left(C_{i}\right.$, $\left.\mu \mathrm{mol} \mathrm{CO} \mathrm{mol} \mathrm{air}^{-1}\right)$. Values are average \pm DS of three replications 63 DAT.

\begin{tabular}{|c|c|c|c|c|}
\hline & $\begin{array}{c}\text { Net Photosynthetic } \\
\text { Rate }(A)\end{array}$ & $\begin{array}{c}\text { Stomatal } \\
\text { Conductance }\left(g_{s}\right)\end{array}$ & $\begin{array}{c}\text { Transpiration Rate } \\
(E)\end{array}$ & $\begin{array}{l}\text { Intercellular } \mathrm{CO}_{2} \\
\text { Concentration }\left(C_{i}\right)\end{array}$ \\
\hline Supplementary light (SL) & $\mu \mathrm{mol} \mathrm{CO} 2 \mathrm{~m}^{-2} \mathrm{~s}^{-1}$ & $\mathrm{~mol} \mathrm{H}_{2} \mathrm{O} \mathrm{m}^{-2} \mathrm{~s}^{-1}$ & $\mathrm{mmol} \mathrm{H}_{2} \mathrm{O} \mathrm{m}^{-2} \mathrm{~s}^{-1}$ & $\mu \mathrm{mol} \mathrm{CO} \mathrm{mol}^{-1}$ \\
\hline Control (NL) & $9.0 \pm 0.3$ & $0.338 \pm 0.010$ & $3.72 \pm 0.64$ & $333 \pm 6$ \\
\hline $\mathrm{R}+\mathrm{B}$ & $8.4 \pm 0.7$ & $0.350 \pm 0.011$ & $3.75 \pm 0.69$ & $340 \pm 5$ \\
\hline $\mathrm{R}+\mathrm{B}+\mathrm{FR}$ & $8.4 \pm 0.7$ & $0.353 \pm 0.010$ & $3.68 \pm 0.56$ & $340 \pm 6$ \\
\hline \multicolumn{5}{|l|}{ Significance $^{(1)}$} \\
\hline NL vs. SL & NS & NS & NS & NS \\
\hline$R+B$ vs. $R+B+F R$ & NS & NS & NS & NS \\
\hline
\end{tabular}

(1) Significance: NS, not significant for $p \leq 0.05$.

\subsection{Fruit Quantitavive and Qualitative Analysis}

Tomato plants grown with $\mathrm{R}+\mathrm{B}$ and $\mathrm{R}+\mathrm{B}+\mathrm{FR}$ produced an average of $2.37 \mathrm{~kg}$ of tomato fruits per plant, $25 \%$ more than plants grown under control light conditions (NL); the same was true of marketable yield (Table 3). In terms of number of fruits harvested, plants grown with SL produced $20 \%$ more tomatoes than those grown with NL (Table 3). Finally, average fruit weight was $84.4 \mathrm{~g}$ (Table 3). In terms of potential yield (including tomatoes that were not harvested), SL produced $2.69 \mathrm{~kg} \mathrm{plant}^{-1}$, $23 \%$ higher than potential production under NL (Table 3). Potential tomato number was $24 \%$ more with SL than with NL (Table 3). 
Table 3. Effects of different SL spectra (R + B vs. R + B + FR) and different light conditions (NL vs. SL) on tomato plant yield, marketable yield, harvested fruit number, average fruit weight, potential yield and potential fruit number. Values are average \pm DS of three replications made during the growing cycle.

\begin{tabular}{|c|c|c|c|c|c|c|}
\hline & \multirow[b]{2}{*}{ Yield } & \multirow{2}{*}{$\begin{array}{c}\text { Marketable } \\
\text { Yield }\end{array}$} & \multirow{2}{*}{$\begin{array}{l}\text { Harvested Fruit } \\
\text { Number }\end{array}$} & \multirow{2}{*}{$\begin{array}{c}\text { Average } \\
\text { Fruit Weight }\end{array}$} & \multicolumn{2}{|c|}{ Potential Production } \\
\hline & & & & & Yield & $\begin{array}{c}\text { Fruit } \\
\text { Number }\end{array}$ \\
\hline $\begin{array}{l}\text { Supplementary } \\
\text { light (SL) }\end{array}$ & $\mathrm{kg}_{\text {plant }}{ }^{-1}$ & $\mathrm{~kg}_{\text {plant }}{ }^{-1}$ & n. plant $^{-1}$ & $\mathrm{~g}$ & $\mathrm{~kg}_{\text {plant }}{ }^{-1}$ & n. plant ${ }^{-1}$ \\
\hline Control (NL) & $1.89 \pm 0.23$ & $1.85 \pm 0.23$ & $22.7 \pm 3.8$ & $81.3 \pm 3.2$ & $2.07 \pm 0.21$ & $25.9 \pm 3.8$ \\
\hline$R+B$ & $2.26 \pm 0.25$ & $2.24 \pm 0.24$ & $26.2 \pm 3.7$ & $85.5 \pm 4.3$ & $2.54 \pm 0.29$ & $31.1 \pm 3.2$ \\
\hline $\mathrm{R}+\mathrm{B}+\mathrm{FR}$ & $2.48 \pm 0.28$ & $2.46 \pm 0.30$ & $28.4 \pm 3.9$ & $86.5 \pm 4.4$ & $2.84 \pm 0.32$ & $34.5 \pm 5.3$ \\
\hline \multicolumn{7}{|l|}{ Significance ${ }^{(1)}$} \\
\hline NL vs. SL & * & * & * & NS & * & * \\
\hline$R+B$ vs. $R+B+F R$ & NS & NS & NS & NS & NS & NS \\
\hline
\end{tabular}

(1) Significance: * $p \leq 0.05$; NS, not significant.

Cumulative production is reported in Figure 3. Supplementary light increased production of the last three harvests with respect to plants under NL (Figure 4).

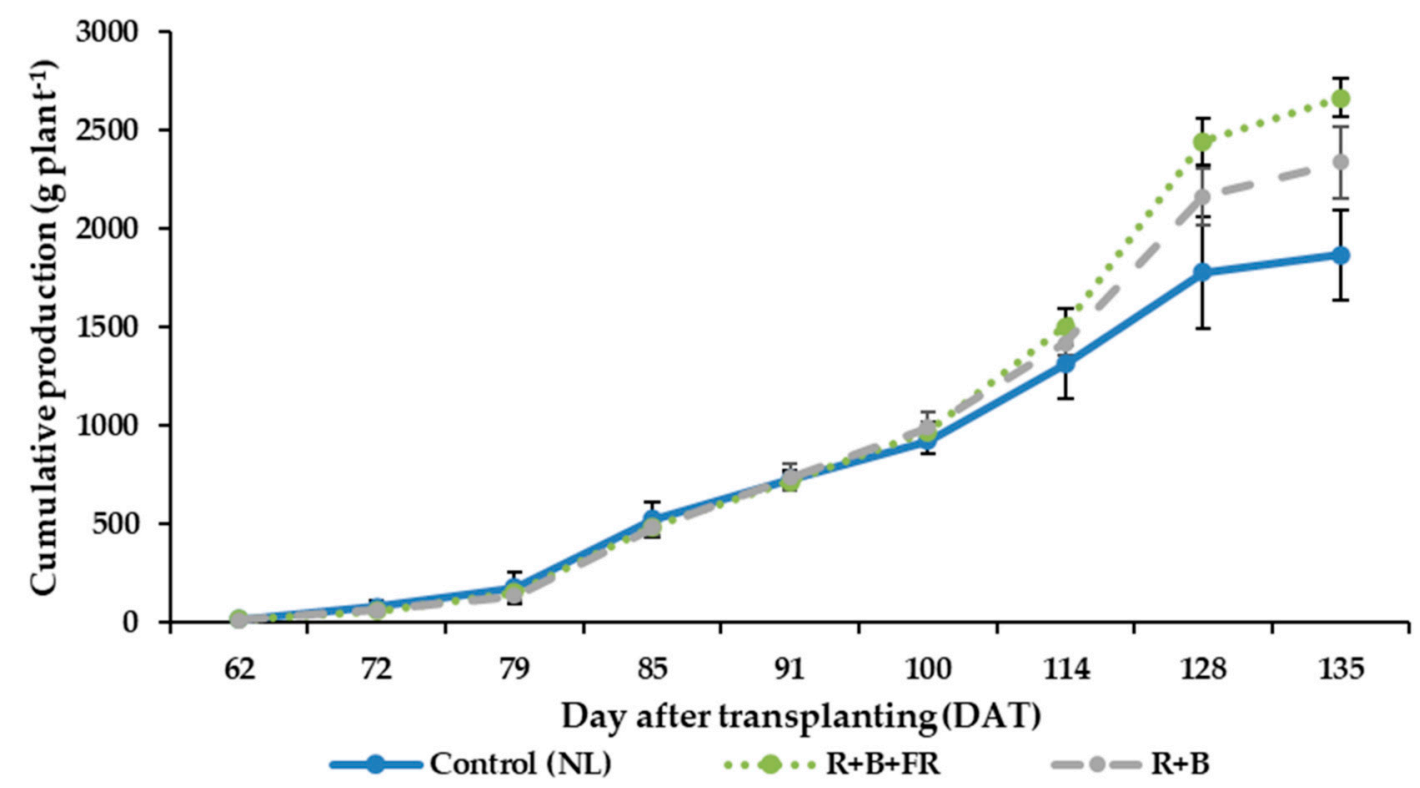

Figure 4. Cumulative production, in g plant $^{-1}$, by plants grown under control (NL), R + B + FR and $\mathrm{R}+\mathrm{B}$ light conditions. Values are average of three replications. Vertical bars represent \pm standard deviation of mean values.

Tomato diameter in the Extra class was not influenced by light treatments. Specifically, $0.3 \%$ of tomatoes harvested had a diameter between $35-40 \mathrm{~mm}, 4.0 \%$ measured $41-47 \mathrm{~mm}, 26 \%$ measured $48-57 \mathrm{~mm}, 57.7 \%$ measured $58-67 \mathrm{~mm}$ and $13.5 \%$ measured $68-82 \mathrm{~mm}$ (figure not shown).

In general, TSS showed an increasing trend from the first to the last harvest (Figure 5a) and was not influenced by SL treatments. Tomatoes grown with NL only showed a TSS $11 \%$ higher than those grown with SL 93 DAT (Figure 5a). No differences between light conditions were found for fruit dry weight (DW), and as in the case of TSS, DW content increased from the first to the last harvest (Figure 5b). 

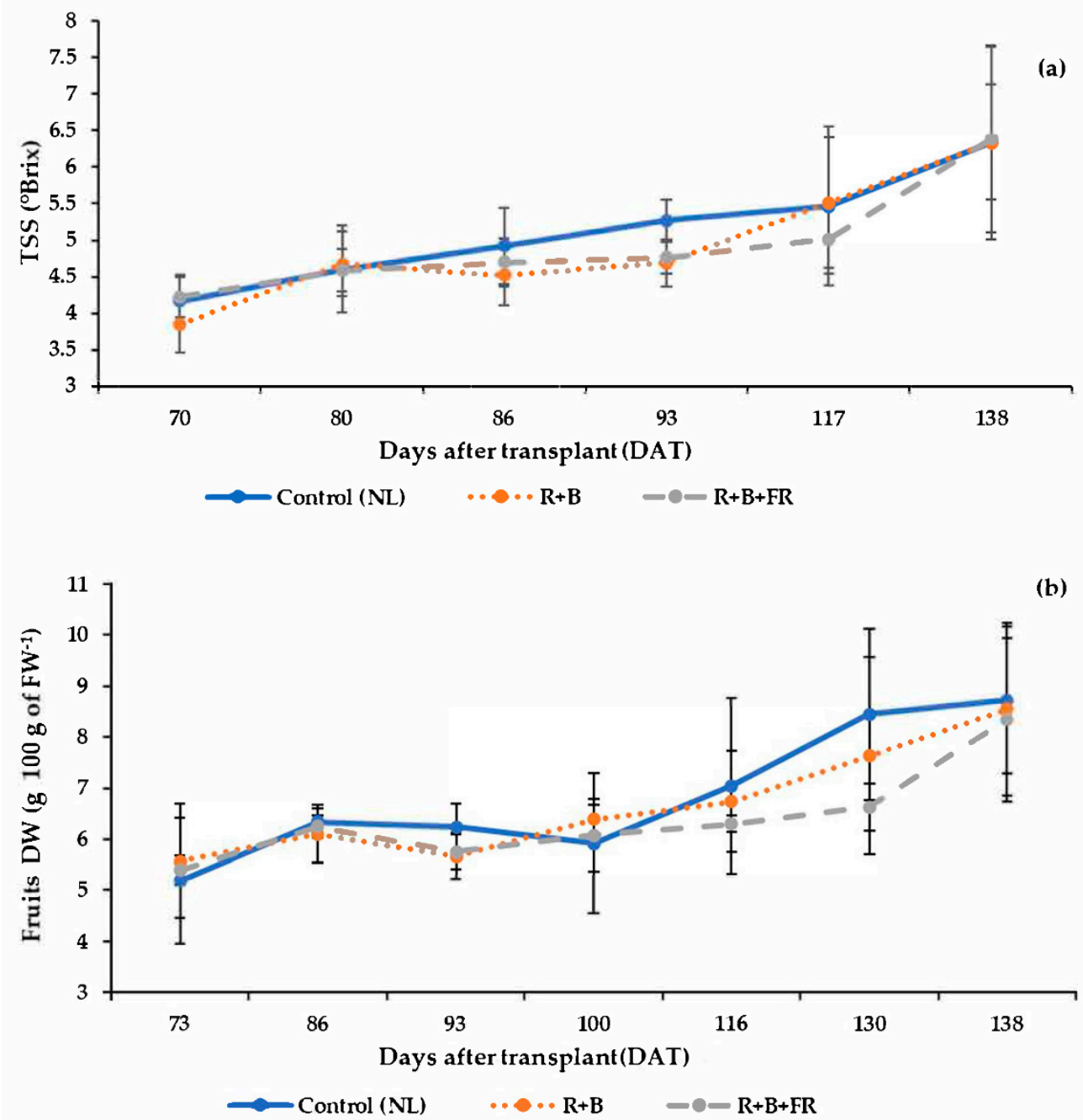

Figure 5. Total soluble solids (TSS) (a) and fruit dry weight (DW) (b) of plants grown under control (NL), R + B + FR, and R + B light conditions. Values are average of three replications. Vertical bars represent \pm standard deviation of mean values.

\subsection{Nutrient Solution Consumption and Water Use Efficiency}

Nutrient solution (NS) uptake, $\mathrm{pH}$ and EC were not influenced by light treatments, but varied during the experiment (Figures 6 and 7). In detail, NS uptake did not vary from NL to SL conditions $(p=0.13)$. The crop absorbed a mean $60.9 \pm 1.5 \mathrm{~L} \mathrm{plant}^{-1}$ (Table 4). On 15 DAT, plants NS uptake was on average $0.13 \pm 0.01 \mathrm{~L}_{\text {plant }}{ }^{-1}$ day $^{-1}$, from 21 to $71 \mathrm{DAT}$ it was $0.62 \pm 0.06 \mathrm{~L} \mathrm{plant}^{-1} \mathrm{day}^{-1}$ and it decreased until the end of the crop cycle (Figure 7). Finally, water use efficiency (WUE) was not affected by supplementary light treatments $(p=0.06)$, but the data trend suggests that with SL, plants tended to use less NS per kg of tomatoes produced (Table 4). 


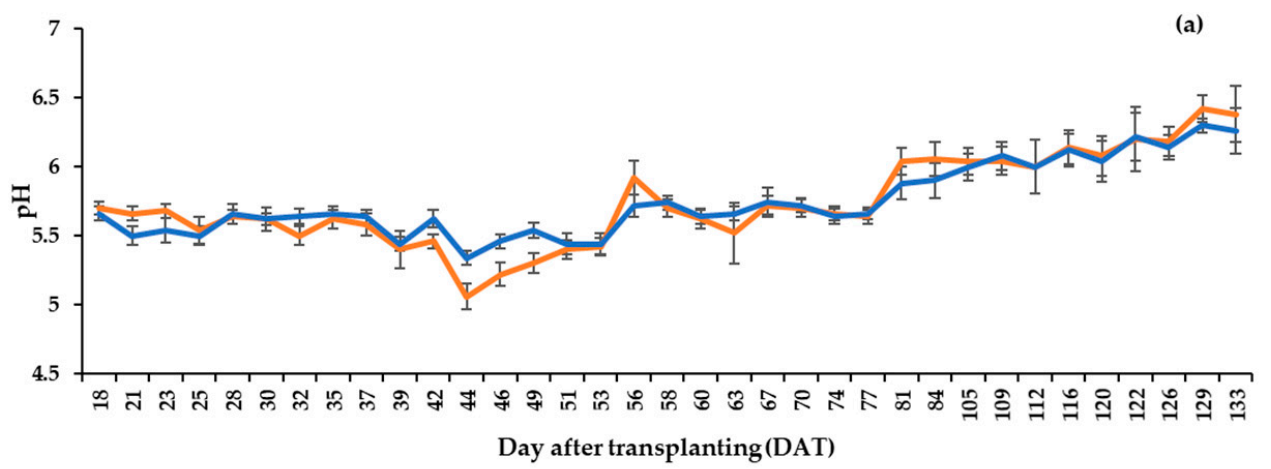

- Before filled up $\quad$ After filled up

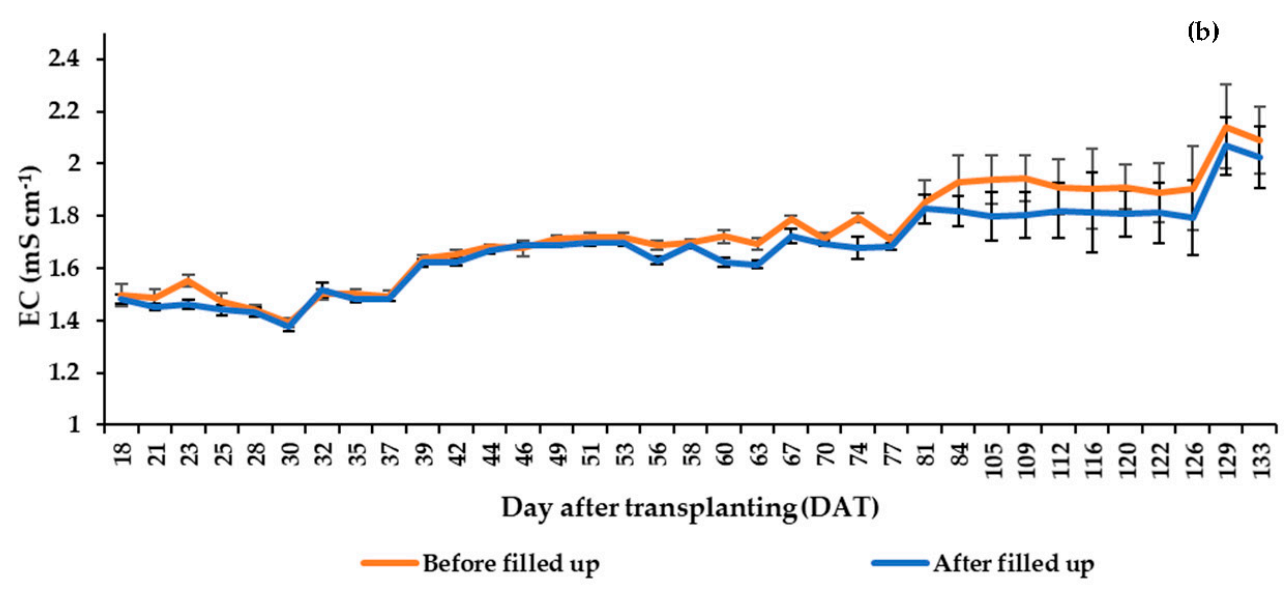

Figure 6. Nutrient solution $\mathrm{pH}(\mathbf{a})$ and $\mathrm{EC}(\mathbf{b})$ before and after tank filling during the growth cycle under control (NL), R + B + FR, and R + B light conditions. Vertical bars represent \pm standard deviation of mean values.

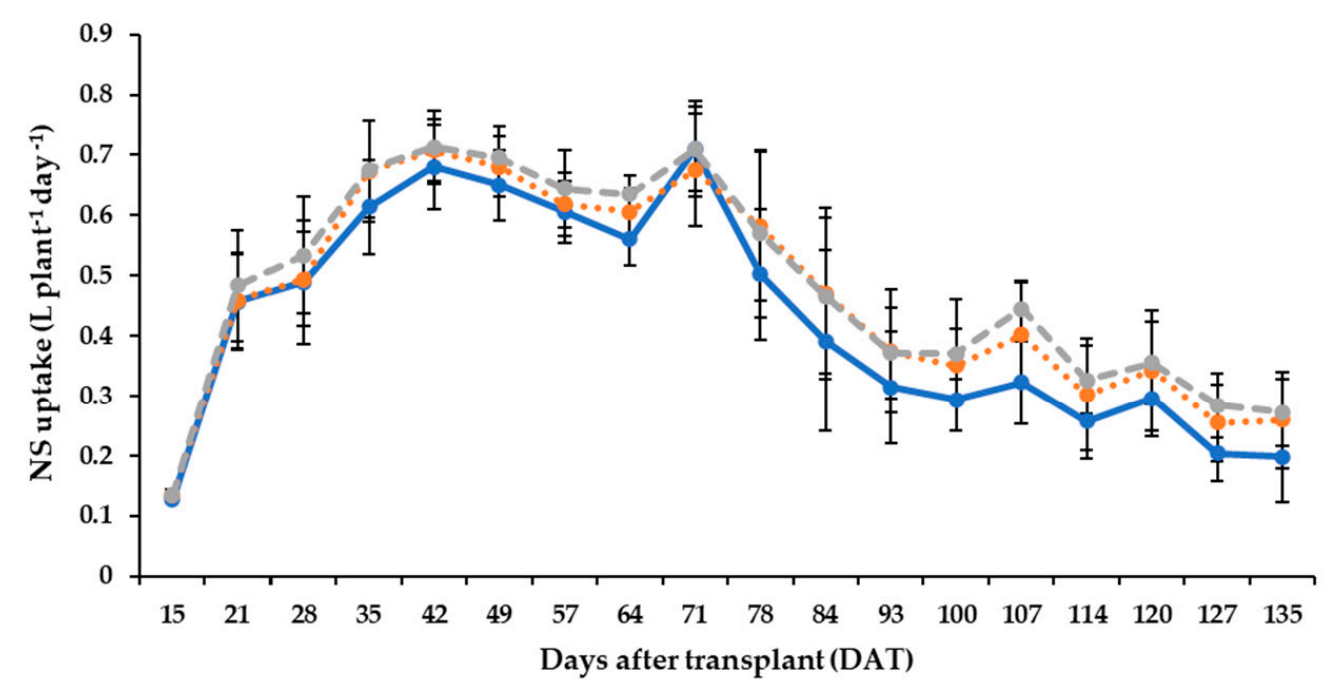

$\longrightarrow$ Control (NL) $\quad \cdots \bullet \mathrm{R}+\mathrm{B} \quad-\bullet-\mathrm{R}+\mathrm{B}+\mathrm{FR}$

Figure 7. Nutrient solution (NS) uptake per plant per day during the growth cycle under control (NL), $\mathrm{R}+\mathrm{B}+\mathrm{FR}$, and $\mathrm{R}+\mathrm{B}$ light conditions. Vertical bars represent \pm standard deviation of mean values. 
Table 4. Effects of light conditions (NL vs. SL) and different SL spectra (R + B vs. R + B + FR) on nutrient solution (NS) uptake and water use efficiency (WUE). Values are average \pm DS of three replications.

\begin{tabular}{ccc}
\hline & NS Uptake & WUE \\
\hline Supplementary light (SL) & L plant $^{-1}$ & $\mathrm{~L} \mathrm{~kg}^{-1}$ \\
Control (NL) & $56.1 \pm 3.4$ & $30.1 \pm 3.1$ \\
R + B & $64.6 \pm 7.2$ & $26.1 \pm 3.8$ \\
R + B + FR & $62.1 \pm 1.3$ & $27.4 \pm 2.5$ \\
Significance & & \\
NL vs. SL & & NS \\
R + B vs. R + B + FR & NS & NS \\
\hline${ }^{(1)}$ Significance: NS, not significant for $p \leq 0.05$.
\end{tabular}

Mean $\mathrm{pH}$ measured in circulating NS was $5.7 \pm 0.46$, with an increasing trend from transplant to the end of the experiment (Figure 6a). Mean EC during the growing cycle was $1.69 \pm 0.18 \mathrm{mS} \mathrm{cm}^{-1}$ (Figure 6b). Like $\mathrm{pH}, \mathrm{EC}$ was higher at the end of cycle than at the beginning (Figure $6 \mathrm{~b}$ ).

\section{Discussion}

\subsection{Supplemental Far-Red Did Not Impact Tomato Growth}

During the experiment, two SL spectra ( + + B vs. R + B + FR) were tested as interlighting, to evaluate their effects on plant growth, photosynthesis, yield, fruit quality, and NS consumption. According to the literature, effects of adding FR to $\mathrm{R}+\mathrm{B}$ in supplementary lighting include elongation of tomato internodes [20], increased fruit production [21], higher dry mass partition to the fruits $[17,22,23]$ and increased photosynthesis [14]. Other studies also found that FR radiation increased leaf area, modifying plant architecture, allowing better light penetration into the canopy [24]. However, most of the studies regarding the FR band were conducted indoors with light supplied exclusively by LED, not under greenhouse conditions where the DLI from interlighting was only a fraction of total DLI (natural light DLI + supplementary light DLI), as in our experiment (Figure 3). During our experiment, the FR effects on tomato plant yield, architecture, photosynthesis, growth and NS absorption were mitigated by FR radiation supplied from solar light. LED interlighting improved crop performance, especially yield, fruits number, marketable yield and potential production, but adding FR radiation on $\mathrm{R}+\mathrm{B}$ background the crop performance were not improve. We therefore postulate that the FR fraction of solar radiation absorbed by tomato plants cultivated in the greenhouse during an autumn-winter cycle diluted the effects of the FR radiation supplied by the LED interlighting. In this regard, Zhen and Bugbee [14] found that only a small percentage of FR was needed to increase photosynthetic efficiency with FR radiation on a $\mathrm{R}+\mathrm{B}$ background. This aspect is important for understanding our results. The percentage of FR photons in sunlight at ground level is around 20\% [23] with a R:FR ratio of about 0.6 at the beginning and end of the day, compared to noon when it ranges from about 1.0 to 1.3 [25]. Additionally, in the case of gas exchange parameters, no differences were found between light treatments (Table 2). Jiang et al. [20] found that FR radiation increased photosynthesis rate $(A)$, stomatal conductance $\left(g_{s}\right)$, transpiration rate $(E)$ and intercellular $\mathrm{CO}_{2}$ concentration $\left(C_{i}\right)$ of tomato plants grown in a solar greenhouse with supplementary $R+B$ and $R+B+F R$ light. This may strengthen our hypothesis regarding a dilution effect of sunlight on the additional FR radiation. In any case, the gas exchange values recorded in our experiment (Table 2) were compatible with the values measured in previous studies [20,26].

\subsection{Supplementary Interlight Increased Tomato Yield}

With the plant density conditions of the present experiment $\left(2.5\right.$ stems $\left.\mathrm{m}^{-2}\right)$, the yield under NL was $4.72 \mathrm{~kg} \mathrm{~m}^{-2}$, whereas under SL it was $5.92 \mathrm{~kg} \mathrm{~m}^{-2}$ (Table 3). The DLI with SL increased fruit production with respect to natural light conditions during the autumn-winter crop cycle. This confirmed the results obtained in a previous experiment run between September 2018 and January 2019 in the same 
greenhouse, where tomato plants cultivated with LED interlighting produced $19 \%$ more than plants grown with natural light (Palmitessa et al., in press) [27]. Moreover, the higher production obtained with SL compared to NL confirmed that during the autumn-winter cycle, the DLI provided by sunlight is not sufficient for tomato plants cultivated in the Mediterranean area [28]. Paucek et al. [29] recorded a higher yield per plant than we did, but during a spring-summer cycle and with a cultivar having a greater average fruit weight than cv. DRW 7723. Nevertheless, the yield obtained by Paucek et al. [29] for plants cultivated with supplementary interlighting was $\sim 24 \%$ higher than under control conditions, especially in spring (almost the same as our figure: $\sim 25 \%$ ). In terms of fruit number and average fruit weight, the plants grown with SL in our experiment had a higher fruit number but the same average fruit weight as plants grown with natural light (Table 3). The same results were obtained by Palmitessa et al. [27], whereas Paucek et al. [29] recorded a higher fruit weight from plants grown with SL than with NL, but the same fruit number. In an experiment conducted by Dorais et al. [28], raising DLI increased the average number of tomatoes per plant, though their average weight did not change with SL treatment. Grimstad [30] attributed the higher yield with SL to greater fruit number rather than to heavier fruits.

\subsection{Supplementary Interlight Did Not Influence Tomato Quality}

Supplementary light did not influence tomato quality (Figure 5). No significant differences in TSS or fruit DW were found in our experiment (Figure 5). Only 93 DAT was the TSS of tomatoes grown with SL treatments 11\% higher than those grown under control conditions (Figure 5a), probably because this period coincided with the lowest DLI from sunlight (Figure 3). These results agree with a previous study where plants grown without SL or with red, blue and white LED did not differ in terms of TSS and tomato DW [31]. The lack of differences may have been due to the fact that in our experiment and that conducted by Lu et al. [31], only 5\% of the SL spectrum was in the blue region. According to Hogewoning et al. [32], the blue band has a fundamental role in regulating plant secondary metabolism and potentially on fruit TSS and DW. This was confirmed by Driever et al. [33] who observed an increase in the TSS of cherry tomatoes when SL with $16 \%$ blue on a red background was used. Finally, our tomatoes averaged $4.7^{\circ}$ Brix (Figure 4), a good result for the autumn-winter crop cycle and this genotype; moreover, TSS increased throughout the cycle, together with nutrient solution EC (Figure 6b).

\subsection{Nutrient Solution Uptake and Water Use Efficiency (WUE)}

Nutrient solution EC and $\mathrm{pH}$ values were not affected by SL treatments, but varied during the growing cycle (Figure 6): mean $\mathrm{pH}$ was $5.7 \pm 0.46$ and increased from the beginning to the end of the cycle (Figure 6); a similar increasing trend was observed for EC: in this case the mean during cultivation was $1.69 \pm 0.18 \mathrm{mS} \mathrm{cm}^{-1}$ (Figure 6b). Plants grown with different light treatments took up the same volume of NS and received the same amount of nutrients (Figure 7). In this regard, our hypothesis was that plants grown with SL were able to absorb more NS than plants grown with NL, especially in December and January, if greenhouse temperature increased. To confirm this, Figure 5 a shows that NS consumption decreased between December and January, when the lowest average temperatures were recorded in the greenhouse (Figure 2). Throughout the crop cycle, total NS consumption averaged $53.5 \pm 1.00 \mathrm{~L} \mathrm{plant}^{-1}$ (Table 4), while EC and pH increased as an effect of corrections to NS composition according to crop stage [34]. Finally, no differences in WUE were found between treatments $(p=0.06$; Table 4), confirming that temperature in the coldest months could have limited uptake of NS and translocation of elements into the fruit.

\section{Conclusions}

The findings of this study confirm that in the Mediterranean region, tomato production benefits when supplementary light is used in an autumn-winter cycle. With LED interlighting, tomato yield increases and fruit quality remains high. The results also demonstrate that a FR component added to 
the $\mathrm{R}+\mathrm{B}$ spectrum did not improve the effects of LED interlighting, probably because the amount of FR supplied by sunlight is sufficient for plant growth and production. While they consumed the same amount of NS, plants grown with LED interlighting produced more tomatoes than those grown under natural light conditions. This suggests important interactions between LED lighting and WUE, which warrant investigation under cultivation conditions characterized by a higher evapotranspiration demand than those of this experiment. Since water is a scarce resource in the Mediterranean region, further studies to assess the impact of supplementary lighting on water use would be worthwhile.

Supplementary Materials: The following are available online at http://www.mdpi.com/2073-4395/10/12/1849/s1: Table S1. Effects of light conditions on fresh weight (FW) and dry weight (DW) of fruits, leaves and stems. Values are averages of three biological replicates 88 DAT. Values are average \pm SE of three biological replicates; Table S2. Effects of light conditions on fresh weight (FW) and dry weight (DW) of fruits, leaves and stems. Values are averages of three biological replicates 110 DAT. Values are average \pm SE of three biological replicates; Table S3. Effects of light conditions on fresh weight (FW) and dry weight (DW) of fruits, leaves and stems. Values are averages of three biological replicates 137 DAT. Values are average \pm SE of three biological replicates.

Author Contributions: Conceptualization: O.D.P., B.L., F.F.M., F.S., A.S., and P.S.; data curation: O.D.P., B.L., F.F.M., F.S., A.S., and P.S.; formal analysis: P.S.; funding acquisition: P.S.; investigation: O.D.P., B.L., F.F.M., F.S., A.S., and P.S.; project administration: P.S.; resources: O.D.P., B.L., F.F.M., F.S., A.S., and P.S.; supervision: P.S.; validation: O.D.P., B.L., F.F.M., F.S., A.S., and P.S.; visualization: O.D.P., B.L., F.F.M., F.S., A.S., and P.S.; writing-original draft preparation: O.D.P.; writing-review and editing: O.D.P., F.F.M., F.S., A.S., and P.S. All authors have read and agreed to the published version of the manuscript.

Funding: This research was funded by the Rural Development Programme of the Apulia Region (Italy) 2014-2020, Submeasure 16.2 (Support for pilot projects and development of new products, practices, processes and technologies, and transfer and dissemination of results obtained by Operational Groups), in the framework of the SOILLESS GO project, project code (CUP) B97H20000990009, paper no. 2.

Acknowledgments: We thank Nicola Gentile for technical assistance during experimental activities in the greenhouse. We also thank the referees who gave us the opportunity to make the manuscript more interesting.

Conflicts of Interest: The authors declare that they do not have any conflicts of interest.

\section{References}

1. Kubota, C.; de Gelder, A.; Peet, M.M. Grenhouse Tomato Production. In Tomatoes; CABI Publishing: Wallingford, UK, 2018; pp. 276-313, ISBN 9781780641942.

2. Palmitessa, O.D.; Paciello, P.; Santamaria, P. Supplemental LED Increases Tomato Yield in mediterranean Semi-Closed Greenhouse. Agronomy 2020, 10, 1353. [CrossRef]

3. Paponov, M.; Kechasov, D.; Lacek, J.; Verheul, M.J.; Paponov, I.A. Supplemental Light-Emitting Diode Inter-Lighting Increases Tomato Fruit Growth Through Enhanced Photosynthetic Light Use Efficiency and modulated Root Activity. Front. Plant Sci. 2019, 10, 1656. [CrossRef] [PubMed]

4. Buttaro, D.; Santamaria, P.; Signore, A.; Cantore, V.; Boari, F.; Montesano, F.F.; Parente, A. Irrigation management of Greenhouse Tomato and Cucumber Using Tensiometer: Effects on Yield, Quality and Water Use. Agric. Agric. Sci. Procedia 2015, 4, 440-444. [CrossRef]

5. Hovi-Pekkanen, T.; Tahvonen, R. Effects of interlighting on yield and external fruit quality in year-round cultivated cucumber. Sci. Hortic. 2008, 116, 152-161. [CrossRef]

6. Hovi, T.; Näkkilä, J.; Tahvonen, R. Interlighting improves production of year-round cucumber. Sci. Hortic. 2004, 102, 283-294. [CrossRef]

7. Särkkä, L.E.; Jokinen, K.; Ottosen, C.O.; Kaukoranta, T. Effects of HPS and LED lighting on cucumber leaf photosynthesis, light quality penetration and temperature in the canopy, plant morphology and yield. Agric. Food Sci. 2017, 26, 101-109. [CrossRef]

8. Bantis, F.; Smirnakou, S.; Ouzounis, T.; Koukounaras, A.; Ntagkas, N.; Radoglou, K. Current status and recent achievements in the field of horticulture with the use of light-emitting diodes (LEDs). Sci. Hortic. 2018, 235, 437-451. [CrossRef]

9. Kusuma, P.; Pattison, P.M. From physics to fixtures to food: Current and potential LED efficacy. Hortic. Res. 2020, 7, 1-9. [CrossRef]

10. Tennessen, D.J.; Singsaas, E.L.; Sharkey, T.D. Light-emitting diodes as a light source for photosynthesis research. Photosynth. Res. 1994, 39, 85-92. [CrossRef] 
11. Lin, K.H.; Huang, M.Y.; Huang, W.D.; Hsu, M.H.; Yang, Z.W.; Yang, C.M. The effects of red, blue, and white light-emitting diodes on the growth, development, and edible quality of hydroponically grown lettuce (Lactuca sativa L. var. capitata). Sci. Hortic. 2013, 150, 86-91. [CrossRef]

12. McCree, K.J. The action spectrum, absorptance and quantum yield of photosynthesis in crop plants. Agric. Meteorol. 1972, 9, 191-216. [CrossRef]

13. Chen, M.; Blankenship, R.E. Expanding the solar spectrum used by photosynthesis. Trends Plant Sci. 2011, 16, 427-431. [CrossRef] [PubMed]

14. Zhen, S.; Bugbee, B. Far-red photons have equivalent efficiency to traditional photosynthetic photons: Implications for redefining photosynthetically active radiation. Plant Cell Environ. 2020, 43, 1259-1272. [CrossRef] [PubMed]

15. Zhen, S.; van Iersel, M.W. Far-red light is needed for efficient photochemistry and photosynthesis. J. Plant. Physiol. 2017, 209, 115-122. [CrossRef]

16. Kim, H.; Yang, T.; Choi, S.; Wang, Y.; Lin, M.; Liceaga, A.M. Supplemental intracanopy far-red radiation to red LED light improves fruit quality attributes of greenhouse tomatoes. Sci. Hortic. 2020, 261, 108985. [CrossRef]

17. Ji, Y.; Ouzounis, T.; Courbier, S.; Kaiser, E.; Nguyen, P.T.; Schouten, H.J.; Visser, R.G.F.; Pierik, R.; Marcelis, L.F.M.; Heuvelink, E. Far-red radiation increases dry mass partitioning to fruits but reduces Botrytis cinerea resistance in tomato. Environ. Exper. Bot. 2019, 103889. [CrossRef]

18. Hoagland, D.R.; Arnon, D.I. The Water-Culture Method for Growing Plants without Soil. Californian Agricultural Experimental Station. Circular 347; University of California: Berkeley, CA, USA, 1950; p. 32.

19. Faust, J.E.; Holcombe, V.; Rajapakse, N.C.; Layne, D.R. The effect of daily light integral on bedding plant growth and flowering. HortScience 2005, 40, 645-649. [CrossRef]

20. Jiang, C.; Johkan, M.; Maruo, T.; Hohjo, M.; Tsukagoshi, S.; Ebihara, M.; Nakaminami, A. Effect of supplemental far-red light with blue and red LED lamps on leaf photosynthesis, stomatal regulation and plant development of protected cultivated tomato. Acta Hortic. 2018, 533-540. [CrossRef]

21. Zhang, Y.; Zhang, Y.; Yang, Q.; LI, T. Overhead supplemental Far-red light stimulates tomato growth under intra-canopy lighting with LEDs. J. Integr. Agric. 2018, 17, 62-69. [CrossRef]

22. Hao, X.; Little, C.; Zheng, J.M.; Cao, R. Far-red LEDs improve fruit production in greenhouse tomato grown under high-pressure sodium lighting. Acta Hortic. 2016, 1134, 95-102. [CrossRef]

23. Kalaitzoglou, P.; van Ieperen, W.; Harbinson, J.; van der Meer, M.; Martinakos, S.; Weerheim, K.; Nicole, C.C.S.; Marcelis, L.F.M. Effects of continuous or end-of-day far-red light on tomato plant growth, morphology, light absorption, and fruit production. Front. Plant Sci. 2019, 10, 322. [CrossRef] [PubMed]

24. Cao, K.; Yu, J.; Xu, D.; Ai, K.; Bao, E.; Zou, Z. Exposure to lower red to far-red light ratios improve tomato tolerance to salt stress. BMC Plant Biol. 2018, 18-92. [CrossRef] [PubMed]

25. Demotes-Mainard, S.; Péron, T.; Corot, A.; Bertheloot, J.; Le Gourrierec, J.; Pelleschi-Travier, S.; Crespel, L.; Morel, P.; Huché-Thélier, L.; Boumaza, R.; et al. Plant responses to red and far-red lights, applications in horticulture. Environ. Exp. Bot. 2016, 121, 4-21. [CrossRef]

26. Arena, C.; Tsonev, T.; Doneva, D.; De Micco, V.; Michelozzi, M.; Brunetti, C.; Centritto, M.; Fineschi, S.; Velikova, V.; Loreto, F. The effect of light quality on growth, photosynthesis, leaf anatomy and volatile isoprenoids of a monoterpene-emitting herbaceous species (Solanum lycopersicum L.) and an isoprene-emitting tree (Platanus orientalis L.). Environ. Exp. Bot. 2016, 130, 122-132. [CrossRef]

27. Palmitessa, O.D.; Montesano, F.F.; Serio, F.; Signore, A.; Santamaria, P. Supplemental lighting with LED for efficient year- round production of soilless tomato in a Mediterranean greenhouse. In Proceedings of the VI International Symposium on Applications of Modelling as an Innovative Technology in the Horticultural Supply Chain-Model.-IT 2019, Molfetta, Italy, 9-12 June 2019. (in press).

28. Dorais, M.; Gosselin, A.; Trudel, M.J. Annual greenhouse tomato production under a sequential intercropping system using supplemental light. Sci. Hortic. 1991, 45, 225-234. [CrossRef]

29. Paucek, I.; Pennisi, G.; Pistillo, A.; Appolloni, E.; Crepaldi, A.; Calegari, B.; Spinelli, F.; Cellini, A.; Gabarrell, X.; Orsini, F.; et al. Supplementary LED interlighting improves yield and precocity of greenhouse tomatoes in the mediterranean. Agronomy 2020, 10, 1002. [CrossRef]

30. Grimstad, S.O. Supplementary lighting of early tomatoes after planting out in glass and acrylic greenhouses. Sci. Hortic. 1987, 33, 189-196. [CrossRef] 
31. Lu, N.; Maruo, T.; Johkan, M.; Hohjo, M. Effects of supplemental lighting with light-emitting diodes (Leds) on tomato yield and quality of single-truss tomato plants grown at high planting density. Environ. Control. Biol. 2012, 50, 63-74. [CrossRef]

32. Hogewoning, S.W.; Trouwborst, G.; Maljaars, H.; Poorter, H.; van Ieperen, W.; Harbinson, J. Blue light dose-responses of leaf photosynthesis, morphology, and chemical composition of Cucumis sativus grown under different combinations of red and blue light. J. Exp. Bot. 2010, 61, 3107-3117. [CrossRef]

33. Driever, S.; Labrie, C.; Verkerke, W. Increasing the level of vitamin C in tomato through light treatments during truss development. Presented at the Wageningen UR Greenhouse Horticolture. Available online: https://edepot.wur.nl/166504 (accessed on 8 April 2011).

34. Sonneveld, C.; Voogt, W. Nutrient solutions for soilless cultures. In Plant Nutrition of Greenhouse Crops; Springer Publishing: Dordrecht, The Netherlands, 2009; pp. 257-275, ISBN 9789048125326.

Publisher's Note: MDPI stays neutral with regard to jurisdictional claims in published maps and institutional affiliations.

(C) 2020 by the authors. Licensee MDPI, Basel, Switzerland. This article is an open access article distributed under the terms and conditions of the Creative Commons Attribution (CC BY) license (http://creativecommons.org/licenses/by/4.0/). 